\title{
The Effectiveness of Buckroyd's Group-Based Therapeutic Approach on Increasing Efficiency Life Style and Improving Body Self-Image
}

\author{
Fariba Hosseini $^{\text {a*(D) }}{ }^{\text {, Yousef Gorgi }}{ }^{\text {b }}$ (D), Afsaneh Javadzadeh ${ }^{\text {a }}$ (D) \\ ${ }^{a}$ Department of Counseling and Guidance, Faculty of Humanities, Islamic Azad University, Khomeini Shahr Branch, \\ Isfahan, Iran. \\ ${ }^{\mathrm{b}}$ Department of Psychology, Faculty of Humanities, Islamic Azad University, Khomeini Shahr Branch, Isfahan, Iran.
}

\begin{tabular}{|c|c|}
\hline$A R T I C L E I N F O$ & $A B S T R A C T$ \\
\hline ORIGINAL ARTICLE & Background: Group teaching can create empathy in teaching sessions. \\
\hline $\begin{array}{l}\text { Article History: } \\
\text { Received: } 27 \text { Mar } 2020 \\
\text { Revised: } 8 \text { Nov } 2020\end{array}$ & $\begin{array}{l}\text { Therefore the objective of the present study was to investigate the } \\
\text { effectiveness of team teaching based on Buckroyd's Method on lifestyle, self- } \\
\text { efficacy and body image structure of the women with obesity in the city of } \\
\text { Isfahan. }\end{array}$ \\
\hline
\end{tabular}

Accepted: 5 Jan 2021

Methods: This study was quasi-experimental with pretest, posttest and control group and follow-up. The statistical population of the study included

*Corresponding Author:

Fariba Hosseini

\section{Email:}

faribahosseini688@yahoo.com

Tel: +989131299907

\section{Citation:}

Hosseini F, Gorgi Y, Javadzadeh A. The Effectiveness of Buckroyd's Group-Based Therapeutic Approach on Increasing Efficiency Life Style and Improving Body SelfImage. Journal of Social Behavior and Community Health (JSBCH). 2021; 5(1): 585-595. all people with obesity referring to clinics in the city of Isfahan from whom 30 women with obesity were selected through purposive sampling from Sepahan Health clinic in 2014 and then they were put into two groups of fifteen (experimental and control). A therapeutic intervention based on Buckroyd Method was administered on the experimental group during 16 two-hour sessions twice a week. The measurement instruments in this study were BMI scale, demographic information form, life style self-efficacy questionnaire and body image questionnaire. Descriptive statistics (mean and standard deviation) and inferential statistics (repeated measures variance) were used to test the hypotheses using SPSS software (version 23) at 0.05 level of error.

Results: The results showed that team teaching based on Buckroyd Method has been effective on the increase of life style self-efficacy $(p<0.001)$ and the improvement of body image $(p<0.001)$ as the mean score of life style self-efficacy and body image structure have increased after team teaching at the post-test stage and it could maintain this increase in time (follow-up stage).

Conclusion: Buckroyd Method can be employed in the increase of life style self-efficacy and body image structure in the obese women.

Keywords: Buckroyd Method, Self-Efficacy, life Style, Body Image, Obesity 


\section{Introduction}

Obesity is a complex and multidimensional state in which the body's over fats are exposed to several health problems (Stefanovics et al., 2018). According to the World Health Organization, defines obesity is called a peripheral accumulation of fat in the body (Yaraghchi et al., 2019). Physiological levels can be defined as the excessive and unusual accumulation of fat in adipose tissue to the level of risk of individual health. Body Mass Index is used to measure body fat (Kolahdozan, 2009). According to this index, obesity refers to large body fat or body mass compared to height, which includes obesity based on body mass, a number above 30 (Mehrabian et al., 2018). Different cognitive and psychological components of obese people are also affected (Webster \& Tiggemann, 2003).

Vulnerable psychological components in obese women can be called Life Style self-efficacy. (Perri \& Corsica, 2003; Chang et al., 2019). Self-efficacy is the level of belief in meeting some challenging tasks (Bandura, 1997). Judgments about self-efficacy are the determining person's choice and regulation of their activities (AbdelKhalek \& Lester, 2017). In obese people, a strong sense of self-efficacy will follow the adhering and observing of a specific diet even if there is only one small change in individual weight (Luszczynska et al., 2005). On the other hand, weight control self-efficacy refers to the person's persuasion about whether they can engage in things that lead to weight loss or weight retention (Clark et al., 1991). Self-efficacy beliefs will cause likely weight loss in obese populations. The existing hypothesis is that self-efficacy beliefs will play an important role in determining cognitive, emotional, and behavioral responses caused by the Inconsistency between standards and success (Elfhag \& Rossner, 2005).

Another vulnerable psychological component in women with obesity is their body image component (Grilo et al., 2019). Body image is the person's understanding of the body size and fitness that comes with the thinking, feeling, and viewpoint of other people towards their body and has a multidimensional structure that includes two independent parts: It is perceptual and perspective (Beintner et al., 2019). The findings show that the body image of obese people is lower than overweight and normal groups because of their specific characteristics (Furnham et al., 2002).

Different methods have been proposed to increase the psychological and communication components of obese people. One of these methods is group training based on the method of Buckroyd (Hosseini et al., 2016; Qalilo et al., 2012). Professor Backroyd is one of the researchers who have studied obesity and eating disorders in women (Asgari et al., 2009). He believes eating in obese people is more affected by emotions than it is caused by hunger. In his studies, Buckroyd uses different theories such as Prochska and Diclemente, Bandora self-efficacy theory, and group value theory. Wei's approach is based on psychological education and has been taken from the theoretical basics of the cognitive-behavioral approach (Buckroyd et al., 2006). His group weight loss program consists of 9 steps: (1) emotional eating, (2) excitement, (3) motivation and ability to change, (4) food monitoring and selection, (5) activity, (6) self-rearing, (7) relationships, (8) self-esteem, (9) physical selfesteem. The Buckroyd program has worked on various aspects of obesity-related psychological issues and has used a psychological education approach that informs the patient about their illness and then gives their education for treatment (Buckroyd, 2011). Currently, one in three people in the world are obese and overweight, and as a result, more than three million people die each year (Canuto et al., 2020).

Therefore, considering the prevalence of obesity among Iranian young women, especially in the age category of 20-30 years, which is the time of marriage and fertility (Alaeeini et al., 2012), the need for health and fitness, self-confidence and self-efficacy are more to reduce physical and psychological problems in this age category. 
The current research vacuum can also be investigated in this point that considering the role of psychological interventions in improving people's attitudes toward themselves and feeling better body image (especially in obese people), this process has remained in past researches. However, group education (As a group) by Buckroyd Method has been used in very small amounts. Accordingly, this study's main issue is to investigate the effect of group education by Buckroyd Method on increasing lifestyle self-efficacy and body image structure in obese women.

\section{Methods}

The study was an educational intervention with pre-test, post-test and follow-up design with experimental and control groups. This study's statistical population was all obese women between 20 and 30 years old who referred to nutrition and diet emanating hospitals in Isfahan in spring and summer 2014. The sampling method was to select one of the four nutrition centers of Isfahan city. Then, 30 women who had inclusion criteria were selected by purposive sampling method and randomly divided into two experimental and control groups so that 30 women were assigned to experimental and control groups by lottery method. The sample size was calculated using Cohen Table and determination of effect size according to $\alpha=0.05, \alpha=0.005, \beta=0.8$, and Kline et al. (2001), which was estimated to be 30 in both groups (each group consisted of 15 people). In each group, 15 patients were placed, but one of the experimental groups was selected during the training, and one person was randomly removed from the control group by the researchers. Inclusion criteria were being in the age category between 20 and 30 years, having BMI above 30, having high school education, lack of pregnancy, having physical health, and being in Isfahan city. Their physical health was confirmed by using the information in their medical record. Exclusion criteria included unwillingness to continue attending educational sessions, absence in two educational sessions, and an acute physical and psychological disorder during the research process. Before education, both groups completed the questionnaires. To observe the study's ethics, the participants' consent to participate in the intervention program was gained and informed of all stages of intervention. Also, the control group was assured that they would receive these interventions after the research process. Also, individuals in both groups were assured that the research results would be published in an anonymous way.

\section{Instrument}

Body Mass Index (BMI): is obtained from weight (to $\mathrm{kg}$ ) to height (m) square. Before the intervention, the experimental and control groups leaned directly to the side of the side to determine the height, shoeless person, and direct to the side of the side. The heel, buttocks, shoulders, and head were in contact with the side. Height was determined by tape meter. High sensitivity digital scale was used to determine weight. Also, after the educational method and one month after that, the height and weight of the two groups were taken again. Those with a BMI above 30 were considered obese (Alaeeini et al., 2012).

\section{Weight-related lifestyle self-efficacy} questionnaire: This questionnaire, designed and constructed by Clark et al. in 1991, has 20 themes based on a five-point Likert spectrum (from 0 to 4 very confident trusts). All the values are directly scoring, and the range of their scores is between 0 and maximum 80 . This 20 -item questionnaire has five subscales of negative emotions (questions 1 to 4), access to food and foods (questions 5 to 8 ), social pressures (questions 9 to 12), physical distress (questions 13 to 16) and positive and fun activities (questions 17 to 20) (Clark et al. 1991). Validity and reliability of the Lifestyle Self-Efficacy Questionnaire related to Weight Control were assessed and confirmed by Navidian et al. (2012). Its validity was assessed and confirmed by confirmatory factor analysis, convergence validity (correlation with scores of Sherr general 
self-efficacy Questionnaire) and divergence (non-correlation with the scores of the Checklist of Psychiatric Symptoms Questionnaire form 90). Reliability of the Weight Control Lifestyle Self-Efficacy Questionnaire by Test-Retest method and calculation of the correlation coefficient of torque on 40 subjects with Body Mass Index more than 25 with distance The correlation coefficient was performed for each dimension of social pressure 0.57 , food access was 0.85 , positive emotions 0.89 , negative emotions 0.91, physical discomfort 0.90, and total questionnaire 0.91 and in terms of internal consistency of its alpha values in the dimensions of social pressure 0.68 , access to food was 0.73 , positive emotions were 0.66 , negative emotions were 0.72 , physical discomfort was 0.65 and the whole questionnaire was 0.88 (Clark et al., 1991).

Body Image Questionnaire: The questionnaire was designed by Cash \& Pruzinsky in 2002 and consisted of 68 substances. In 1985, Cash et al. used the questionnaire for an international study of body image. Among 30,000 participants, 2,000 were randomly selected and classified based on age and sex. The body image questionnaire consisted of three scales: satisfaction scale from different physical wards (questions 60-68), individual attitude about weight (questions 59, 58, $57,56,20$ ) and self-body questionnaire (questions 1 to 19 and questions 21 to 55). Each of these areas has 5 scores so that the score of 1 is considered completely opposite, and the score of 5 is considered completely agreeable. A higher score indicates higher satisfaction. In the body image questionnaire, the satisfaction of different parts of the body, including the face, upper body, middle trunk, and lower trunk, muscle consistency, weight, height, and appearance, score 1 for completely dissatisfied state and 5 for the completely satisfied state. The validity of the questionnaires was assessed and confirmed by Cash et al. (1990). Its reliability was reported to be 0.81 . Cronbach's alpha coefficient was 0.85 .

\section{Research Implementation Process}

After obtaining the necessary permits and sampling (according to what was mentioned), the obese subjects (30 females) were randomly assigned to experimental and control groups (15 women in experimental and 15 females in the control group). The experimental group received 16 sessions of intervention based on the Buckroyd method for two months with two sessions of 90 minutes each, per week. At the end of the education, a post-test was performed on both groups and after one month a follow-up was performed. However, the control group received no intervention during the study. The researcher held the treatment sessions. The code ethics for this article is IR. IAUKHSH. REC.1396.74 Which was received from Khomeini Shahr University of Medical Sciences.

Data were analyzed using mean, and standard deviation in descriptive statistics and inferential statistics section, repeated measure ANOVA (for testing the research hypothesis), Mauchly sphericity default-test was used to investigate the default of sphericity in this test. The data were analyzed by SPSS software version 23 . The significance level was considered 0.05 .

\section{Results}

Demographic findings showed that of 28 participants, 9 (31\%) were single, and 19 (68\%) were married. Also, among 28 participants, 7 (25\%) had a diploma, 3 (10.7\%) had an Associate Degree, 11 (39.3\%) had a bachelor's degree, and 7 (25\%) had a master's degree. It should be noted that by investigating the relationship between demographic variables (marriage and education level) with lifestyle and body image self-efficacy variables (research-related variables) using Ty-Kandal correlation test (to investigate the relationship between lifestyle and body image selfefficacy) and Spearman test (to investigate the relationship between lifestyle self-efficacy and body image with education level), it was found that there is no significant relationship between dependent and demographic variables in this 
study. In addition, no significant relationship was observed between demographic variables (marriage and education level) and Body Mass Index (BMI) of the subjects present in the study. Now descriptive findings of the study are being investigated.

The kolmogorov-Smirnov test was performed to test the normal distribution of data, which showed that the distribution of data in lifestyle and body image self-efficacy scale was normal in both groups at all stages. The P-value of lifestyle and body image self-efficacy in the Kolmogorov-Smirnov test was $(\mathrm{p}=0.474$ and $\mathrm{p}$ $=0.625)$. Also, to evaluate the homogeneity of variances, the Lon test was performed which showed the equal condition of variance in both lifestyle and body image self-efficacy variables ( $p>0.05)$. On the other hand, for assessing the uniformity of variance, the porous Mauchly test was performed which was not significant for lifestyle and body image self-efficacy components and it can be said that the condition of ANOVA sphericity uniformity was met in two variables of lifestyle and body image selfefficacy $(\mathrm{p}>0.05)$.
Table 1 summarizes the interventions. Table 2 also provides descriptive findings. Finally, Table 3 presents the findings related to repeated measures variance.

The results of a repeated measure ANOVA table show that the mean scores of lifestyle and body image self-efficacy, regardless of the effect of grouping during post-test and follow-up stages, have changed significantly, which is a significant difference compared to pre-test $(\mathrm{P}<$ 0.001). On the other hand, the results second row in both lifestyle and body image selfefficacy variables indicate that grouping variable (teaching the macro method) regardless of the stages (pre-test, post-test, and follow-up) had a significant effect on lifestyle self-efficacy and body image $(\mathrm{P}<0.001)$. This means that the effect of Buckroyd method was significant compared to the control group. Finally, the row of stage interaction and grouping indicates that the training of the Buckroyd method with the interaction of stages had a significant effect on the test stages (pre-test, post-test, and follow-up) in lifestyle and body image self-efficacy variables $(\mathrm{P}<0.001)$.

Table 1. Summary of treatment sessions

\begin{tabular}{|c|c|c|}
\hline Session & Topic & Summary of Sessions \\
\hline One & $\begin{array}{l}\text { Orientation } \\
\text { session and } \\
\text { motivation and } \\
\text { strengthening } \\
\text { the desire for } \\
\text { change }\end{array}$ & $\begin{array}{l}\text { Introducing the program and reviewing it, an overview of the benefits of group } \\
\text { counseling, filling out questionnaires by participants, welcome, introducing members, } \\
\text { group rules plan and getting satisfaction from members committed to attend group } \\
\text { meetings, to expression of fears and fears, to discuss obesity and its effect on one's life, } \\
\text { to discuss confidence and to mention ways to increase that homework. : Writing other } \\
\text { solutions to raise confidence }\end{array}$ \\
\hline Two & $\begin{array}{l}\text { Motivation and } \\
\text { strengthening } \\
\text { the desire for } \\
\text { change }\end{array}$ & $\begin{array}{l}\text { Reviewing the previous session, studying homework, introducing the theory of Prochska } \\
\text { change and the model of stages of change and discussion about it, the reasons for } \\
\text { changing and not changing weight and sharing them with the group, examples of other } \\
\text { life and determining the point where they are }\end{array}$ \\
\hline Three & $\begin{array}{l}\text { Motivation and } \\
\text { strengthening } \\
\text { the desire for } \\
\text { change }\end{array}$ & $\begin{array}{l}\text { Reviewing the previous session, studying homework, discussing motivation, providing } \\
\text { strategies to strengthen motivation, emphasis on determining the goal, introducing the } \\
\text { self-regulatory idea, working food and mood sheet, weight line/lifeline training, } \\
\text { homework: daily filling of food and mood leaf work }\end{array}$ \\
\hline Four & $\begin{array}{l}\text { Focus on } \\
\text { emotions }\end{array}$ & $\begin{array}{l}\text { Reviewing the previous session, homework study: mentioning the factors of filling and } \\
\text { not filling the sheet, discussing emotional eating, the difference between eating } \\
\text { emotionally and eating commonly, not naming the excitement, members' awareness of } \\
\text { their excitement, homework: worksheet Food and mood, Introducing new strategies for } \\
\text { managing emotions }\end{array}$ \\
\hline
\end{tabular}


Table 1. Summary of treatment sessions

\begin{tabular}{ccl} 
Session & \multicolumn{1}{c}{ Topic } & \multicolumn{1}{c}{ Summary of Sessions } \\
\hline & & $\begin{array}{l}\text { Reviewing the previous session, studying tasks, studying family members' emotion, } \\
\text { discussing emotion management, the root of different emotion, providing cognitive- } \\
\text { behavioral solutions for management. Their excitement and overeating, chamber or } \\
\text { tanker technology, homework: Food and mood worksheet, new solutions for emotion } \\
\text { management }\end{array}$
\end{tabular}

Six Focus on

Reviewing the previous session, studying tasks, discussing the causes of food abuse, providing stress management and emotional hyperemesis control, remixing training, safe face imagination technology, emotion regulation technology, homework: training of methods presented in the meeting

Reviewing the previous session, studying tasks, providing a food planning sheet and a description of it, studying dietary beliefs and discussing false food habits, food

Seven Eating habits and eating habits replacement: a strategic change in the food menu, homework: daily shopping cart, filling daily sheet work

Review of the previous session, studying tasks, healthy eating ways, recognizing happy foods, nerve-sedated foods, aging foods, and diets for having good ethics

Eight Eating habits and eating habits

Home Work: Food Experience Note on the discussion of this meeting, filling out daily leaf work

Nine Reviewing

Review of motivation, emotional eating discussion, review of food habits and eating sessions attitude

Group members' dialogue with each other about experience of group attendance, mating, using people in place of food, trusting each other, description of attachment theory in

Ten Communications simple language, support cycle method, homework: calling and putting each other in contact with the topics discussed in the group, filling the sheets

Reviewing the previous session, studying tasks, discussing the relationship between emotion management and human interactions, attachment from The Viewpoint of

Eleven Communications Buckroyd, Home Work: Determining the Type of Attachment by the Individual and A Short Description about it

Reviewing the previous session, studying tasks, discussing the history of exercise activities of the members of the group, a brief description of Bandora's self-efficacy

Twelve Activity theory, exercise advantages, the characteristics of a sports program and designing an appropriate exercise program, disadvantages of devices and inappropriate slimming methods, homework: planning for a group march

What is self-esteem when reviewing the previous session? Difference between selfesteem and self-esteem, the relationship between self-esteem and obesity, strategies for increasing self-esteem, introducing the voice book of self-esteem

Thirteen Self-esteem Home Work: Listen to the audiobook and provide more solutions to enhance self-esteem

Body image and Review of the previous session, questions about members' opinions about their bodies,

Fourteen physical selfvisualizing going to a guest, definition of body image, confounding factors in body image Home: Listen to an audiobook esteem

Body image and

Reviewing the previous session, discussing the effect of positive body image, negative

Fifteen physical self- for improving body image esteem body image effect, body image communication, and eating behavior, providing solutions

Fifteen physical self- for improving body image

Home Page: Writing letters to other members of the group

Sixteen $\begin{aligned} & \text { Evaluation and } \\ & \text { closing }\end{aligned}$

Requests from members to present reports on progress in the topics discussed in group meetings, review written letters, reviewing suggestions, filling post-test questionnaires, closing group meetings 
Table 2. Descriptive findings of lifestyle self-efficacy scores and body image in the experimental and control groups in the pre-test, post-test and follow-up stages

\begin{tabular}{clcccc}
\multirow{2}{*}{ Groups } & & \multicolumn{2}{c}{ Lifestyle self-efficacy } & \multicolumn{2}{c}{ Body image } \\
\cline { 3 - 6 } Experiment Group & Steps & Standard Deviation & Mean & Standard Deviation & Mean \\
\hline \multirow{5}{*}{ Control Group } & Post-test & 12.78 & 47.57 & 23.37 & 220.07 \\
& consistency & 11.66 & 57.57 & 12.01 & 246.93 \\
& Pre-test & 10.71 & 58.92 & 11.22 & 245.36 \\
& Post-test & 13.23 & 40.78 & 27.19 & 219.64 \\
& consistency & 15.34 & 40.42 & 23.40 & 216.21 \\
\hline
\end{tabular}

Table 3. comparison of scores of two groups of experimental and control in lifestyle and body image self-efficacy variables in the pre-test, post-test and follow-up stages

\begin{tabular}{llccccc} 
Component & \multicolumn{1}{c}{ Group } & Total squares & $\begin{array}{c}\text { Freedom } \\
\text { Degree }\end{array}$ & $\begin{array}{c}\text { Average } \\
\text { squares }\end{array}$ & F & $\begin{array}{c}\text { Significance } \\
\text { Level }\end{array}$ \\
\hline \multirow{2}{*}{ Lifestyle self- } & Time & 185086.29 & 1 & 185086.29 & 403.36 & 0.001 \\
efficacy & Group & 4214.58 & 1 & 4214.58 & 9.18 & 0.005 \\
& Time \& Group & 965.16 & 1.21 & 792.79 & 20.65 & 0.001 \\
& Time & 43112560.5 & 1 & 4312560.5 & 3681.31 & 0.001 \\
Body image & Group & 9923.44 & 1 & 9923.44 & 8.47 & 0.007 \\
& Time \& Group & 4807.45 & 1.06 & 4503.72 & 35.09 & 0.001 \\
\hline
\end{tabular}

\section{Discussion}

This study aimed to investigate group education's effectiveness based on Buckroyd Method on lifestyle and body image self-efficacy in women with obesity aged 20-30 years in Isfahan. The results showed that group education based on the Buckroyd method effectively increased lifestyle self-efficacy and improved body image.

In the effect of Buckroyd's educational method on self-efficacy on obese women's lifestyle, this result is in line with the findings of Navidian et al. (2012). Their research studied the relationship between lifestyle self-efficacy related to weight control with overweight and obesity. They found that weight control, especially in triple social pressure situations, food access, and experience of positive emotions in obese people is lower than normal-weight individuals. Therefore, it is necessary to pay attention to increasing and supporting individual self-efficacy in weight loss programs. This study's results are in line with Navidian et al. (2012) research on the effectiveness of motivational interviewing as a psychotherapy strategy on increasing lifestyle self-efficacy related to weight.

Psychological variables such as self-efficacy play an important role in weight gain or success in reducing and maintaining it (Elfhag \& Rossner, 2005). Self-efficacy beliefs will follow possible weight loss in obese populations. The existing hypothesis is that self-efficacy beliefs will play an important role in determining cognitive, emotional, and behavioral responses caused by the inconsistencies between standards and successes. In group therapy of Buckroyd based on cognitive behavioral therapy, using behavioral tests to look at patients to test new behavior methods and helping them to test their expectations according to the consequences of behavior change and identifying and systematic evaluation of dysfunctional thoughts and hypotheses improves the level of self-efficacy in person (Martin et al., 2004). In group education conducted in this study, Bandora's self-efficacy theory was investigated. Learning is the main key to this theory, and when one observes that others are behaved and succeed, they will take 
that behavior. Therefore, the group members are shocked to see the success of other members in different fields (e.g., sports) and try to experience their success. A successful experience will be a powerful tool for future success. In group training conducted in The Buckroyd Training Sessions, by encouraging individuals to pair in the group and doing assignments in a couple, and with the questions raised about other sports experiences, successful experiences as well as failure experiences in their lives and other members of the group and with verbal encouragement selected by the leader and other members,

In the study of the results of this study, based on the effectiveness of group training based on The Buckroyd Method on body image of obese women, this result is in agreement with the findings of Qalilo et al. (2012) on the effectiveness of friendly behavior as one of the aspects of positive effects and also negative and positive feelings about body shape on life satisfaction of women. Also, Asgari et al. (2009) showed a significant negative relationship between body image and nutritional disorders.

Myers and Diner (2009; quotes Qalilo et al., 2012) concluded that the higher the life satisfaction rate, the more susceptible the person experienced positive emotions and emotions. This result can be noted that friendly behavior causes people to find many friends and establish an emotional relationship with them and this relationship causes positive emotions to experience. Friends can be supportive/be a strong support in stressful situations and these factors lead to a greater sense of mental peace. If women have a positive image of their body in mind, they will be more satisfied with their lives, gain more confidence, enjoy their relationships and thus experience a life of happiness. This friendly behavior is based on people's interactions, participation in society, and group and collective circles.

In the educational and therapeutic sessions held in this study, the factors affecting the formation of body image including (1) family, (2) friends, (3) media, (4) social and cultural factors and (5) personality characteristics were described in detail for the subjects. Members were asked to speak of their personal experiences for the group. This meeting's result was that the group members must take a negative picture of their current negative body image and move it towards positive. Having a positive body image in mind has positive effects on the individual's physical and mental health. This positive image increases self-esteem and leads to a more positive and healthy approach to eating. In other words, a person who values their body does not eat anything. A positive body image also causes the person to accept their body as he is and is resistant to unreal pressures and, consequently, less depression. Therefore, their mind and power are growing and expanding other aspects of their life.

Negative body image occurs when a person has unpleasant thoughts and feelings about his or her body. These unpleasant thoughts come to the person when there is a difference between their ideal body's expectation and what is actually seen. A different body image of oneself makes the person choose non-healthy food habits. When people restrict their food to reduce their weight, food will turn into their enemy and they will feel guilt-free when eating the food of their choice. While a positive body image allows a person to enjoy their food easily and freely and without feeling guilty (Furnham et al., 2002). Also, strategies were presented for improving their body image in the Buckroyd method. They were asked to accept and love themselves as they are, to focus on their personality, not just to see positively on their body, to be careful about the different consequences of communication with the media, to participate in the party, to choose their clothes to reach the desired weight. Members were also asked to think about these questions, and what changes would be caused if they loved their bodies? What effect will it have on their health care, teeth, appearance, rest, clothing, and the food they are eating? These conditions' totality caused the significant effect of 
the Buckroyd method on self-efficiency of lifestyle and body image in obese women.

The present study was faced with limitations such as restrictions on BMI (BMI between 25 and 30 ), age restrictions (age range 20-30 years), and geographical limitation (Isfahan city). Therefore, it is recommended that this study be conducted in other BMI ranges, different age groups, and other cities.

\section{Conclusion}

In a final summation, it could be said that considering the significant effect of Buckroyd educational method on self-efficiency of lifestyle and body image of women with the obesity age range of 20-30 years, it seems necessary to use different psychological intervention methods in addition to nutritional suggestions and treatments that are considered for these people, it seems necessary to use different psychological intervention methods to improve these vulnerable components. Accelerate the physiological treatment process.

\section{Conflict of interest}

Authors declare no conflict of interest during the study period.

\section{Acknowledgments}

The researchers would like to thank all the participants who contributed to the study.

\section{Authors' Contribution}

Conceptualization, F.H.; Methodology, Y.G.; Formal Analysis, Y.G.; Investigation, F.H.; Writing -Review \& Editing, A.J.; Supervision, Y.G.; Writing -Original Draft, F.H.

All authors read and approved the final manuscript and are responsible about any question related to the article.

\section{References}

Abdel-Khalek, A.M., Lester, D. (2017). The association between religiosity, generalized selfefficacy, mental health, and happiness in Arab college students. Personality and Individual Differences, 109, 12-16.
Alaeeini, E., Mirza Mohammad Alipour, A., Nourballa, A.A., Agah Hariss, M. (2012). Effectiveness on modified adjusted emotional eating, emotional eating and weight management in obese and overweight women. health psychology, 2(3), 21-31. [Persian]

Asgari, P., Pasha, G.H., Aminian, M. (2009). The relationship between emotion regulation, emotional stressors of life and body image and eating disorders in women. Thought and behavior, 4(13), 65-78. [Persian]

Bandura, A. (1997). Self-Efficiency: The Exercise of Control. 1st Ed. New York: W. H. Freeman Company.

Beintner, I., Emmerich, O.L.M., Vollert, B., Taylor, C.B., Jacobi, C. (2019). Promoting positive body image and intuitive eating in women with overweight and obesity via an online intervention: Results from a pilot feasibility study. Eating Behaviors, 34, 101-106.

Buckroyd, J. (2011). Understanding Your Eating: How to eat and not worry about it. Milton Keynes, Open University Press.

Buckroyd, J., Rother, S., Stott, A. (2006). Weight loss as a primary objective of therapeutic groups for obese women: two preliminary studies. British Journal of Guidance \& Counseling, 34(2), 245-265.

Cash, T.F., Mikulka, P.J, Brown, T.A. (1990). Attitudinal body-image assessment: factor analysis of the body-self relations questionnaire. Journal of Personality Assessment, 55(1-2), 13544.

Cash, T.F., Pruzinsky, T. (2002). A negative body image: Evaluating epidemiological evidence, body image: A Handbook of Theory, Research, and Clinical Practice. New York: Guildford Press.

Cash, T.F., Winstead, B.A., Janda, L.H. (1985). Your body, yourself: A psychology today reader survey. Psychology Today, 19(7), 22-26.

Chang, M., Schaffir, J., Brown, R., Wegener, D.T. (2019). Mediation by self-efficacy in the relation between social support and dietary intake in low-income postpartum women who 
were overweight or obese. Appetite, 140, 248-254.

Clark, M.M., Abrams, D.B., Niawa, R.S., Eaton, C.A., Rossi, J.S. (1991). Self-efficiency in eight management. Journal of Consulting and Clinical Psychology, 59, 739-744.

Elfhag, K., Rossner, S. (2005). Who succeeds in maintaining weight loss? A conceptual review of factors associated with weight loss maintenance and weight regain. Obesity Review, 6(1), 67-85.

Furnham, A., Badmin, N., Sneade, I. (2002). Body image dissatisfaction: gender differences in eating attitudes, self-esteem, and reasons for exercise. Journal of Psychology, 136(6), 581596.

Grilo, C.M., Ivezaj, V., Lydecker, J.A., White, M.A. (2019). Toward an understanding of the distinctiveness of body-image constructs in persons categorized with overweight/obesity, bulimia nervosa, and binge-eating disorder. Journal of Psychosomatic Research, 126, 109114.

Hosseini, F., Gorgi, Y., Javadzadeh, A. (2016). The Effectiveness of Buckroyd's Group-Based Therapeutic Approach on Increasing Self-Esteem and Improving Eating Attitude of Obese -20 to 30-Year-Old Females in Esfahan. Journal Education Community Health, 3(1), 43-50. [Persian]

Kline, G., Honaker, J., Joseph, A., Scheve, k. (2001). Analyzing Incomplete Political Science Data; an Alternative Algorithm for Multiple Imputations. American Political Science Review, 95(1), 49-69.

Kolahdozan, M. (2009). Prevention and treatment of diseases (with improved lifestyle). Publisher: University of Medical Sciences, Isfahan, Iran. [Persian]

Luszczynska, A., Gutierrez-Dona, B., Schwarzer, T.R. (2005). General self-efficacy in various domains of human functioning: Evidence Five Countries. International Journal of Psychology, 40(2), 80-89.

Martin, P.D., Dutton, G.R., Brantley, P.J. (2004). Self-efficiency as a predictor of weight change in
African-American women. Obesity Research, 12(4), 646-651.

Canuto, R., Garcez, A., Souza, R. V., Kac, G., Olinto, M. T. A. (2020). Nutritional intervention strategies for the management of overweight and obesity in primary health care: A systematic review with meta analysis. Obesity Reviews, 22 (3), 126-151.

Mirza Mohammad Alaeeini, E., Alipour, A., Nourballa, A.A., Agah Hariss, M. (2012). Effectiveness on modified adjusted emotional eating, emotional eating and weight management in obese and overweight women, health psychology, 2(3), 21-31. [Persian]

Mehrabian, F., Omidi, S., Mahdavi Roshan, M., Mirzaee, M. (2018). Correlation between Nutritional Behavior, Obesity, and Overweight in Female Elementary School Students in Anzali. Journal of health, 9 (3), 291-301. [Persian]

Navidian, A., Abedi, M.R., Baqban, I., Fatehi Zadeh, M., Pour Sharifi, H. (2010). The impact of motivational interviewing on the weight selfefficacy lifestyle, Journal of Health Psychology, 2(12), 21-35. [Persian]

Navidian, A., Kerman Saroei, F., Imani, M. (2012). Efficacy lifestyle weight control overweight and obesity, endocrinology and metabolism magazine, 4(6), 556-563. [Persian]

Perri, M.G., Corsica, J.A. (2003). Treatment of Obesity, In S.I. Leuelyn, \& P. Kennedy (Eds.), Handbook of Clinical Health, Psychology, New York, John Wiley \& Sons.

Qalilo, K., Abolqasemi, A., Dehqan, H., Imani, H. (2012). Relationship between friendly behavior and body image with life satisfaction in women. Journal of Mazandaran University of Medical Sciences, 22(97), 139-146. [Persian]

Stefanovics, E.A., Potenza, M.N., Pietrzak, R.H. (2018). The physical and mental health burden of obesity in U.S. veterans: Results from the National Health and Resilience in Veterans Study. Journal of Psychiatric Research, 103, 112-119.

Webster, J., Tiggemann, M. (2003). The relationship between women's body satisfaction 
and self - image across the life span: The role of cognitive control. Journal of Genetic psychology, 164(2), 241- 252.

Yaraghchi, A., Jomehri, F., Seyrafi, M., Kraskian

Mujembari, A., Mohammadi Farsani, G. (2019).
The Effectiveness of Acceptance and Commitment Therapy on Weight Loss and Cognitive Emotion Regulation in Obese Individuals. Iran Journal Health Education Health Promotion, 7(2), 192-201. [Persian] 